\title{
Effects of polyelectrolytes on the hardness of borax decahydrate crystals
}

\author{
Sevgi Polat ${ }^{1}$, Perviz Sayan ${ }^{2 *}$ \\ ${ }^{1}$ Marmara University, Department of Chemical Engineering, Istanbul 34722, Turkey, ORCID ID orcid.org/0000-0002-0934-2125 \\ ${ }^{2}$ Marmara University, Department of Chemical Engineering, Istanbul 34722, Turkey, ORCID ID orcid.org/0000-0003-4407-6464
}

\section{ARTICLE INFO}

\section{Article history:}

Received 11 January 2019

Received in revised form 02 December 2019

Accepted 16 December 2019

Available online 31 December 2019

\section{Research Article}

DOI: $10.30728 /$ boron. 511783

\section{Keywords:}

Borax decahydrate,

Crystal hardness,

Polyelectrolyte,

PRS model.

\begin{abstract}
The hardness of borax decahydrate crystals was measured using cationic polyelectrolytes of FO4115, FO4400 and FO4990 with anionic polyelectrolytes of AN923, AN930 and AN999 as an additive. The measurements were carried out in the indentation load range of $10 \mathrm{~g}$ to $30 \mathrm{~g}$. It was determined that the Vickers hardness $\left(\mathrm{H}_{\mathrm{v}}\right)$ decreased with increasing applied load, showing that the borax decahydrate crystals exhibited an indentation size effect. Vickers microhardness measurements revealed that pure borax decahydrate crystals had a brittle structure, yet the crystals obtained in additive media were categorized as a soft material. The proportional specimen resistance model was applied to determine the load-independent microhardness. The crystal hardness of borax decahydrate was found to change depending on the type and concentration of polyelectrolyte used. In addition to the mechanical properties, the thermal and physical characteristics of borax decahydrate crystals were investigated by thermogravimetric and Fourier transform infrared spectroscopy analysis. The characterization results confirmed that the polyelectrolytes were adsorbed on the crystal's surface.
\end{abstract}

\section{Introduction}

Boron minerals have a wide range of applications, including ceramics, glass, metallurgy, agriculture, medicine, cosmetics, automotive, communication, insulation, and energy [1]. Borax decahydrate $\left(\mathrm{Na}_{2} \mathrm{~B}_{4} \mathrm{O}_{7} \cdot 10 \mathrm{H}_{2} \mathrm{O}\right)$ is one of the most important boron compounds commercially. Of the approximately 150 known boron-containing minerals, only a small number are commercially important, such as borax decahydrate, colemanite, and ulexite. Borax decahydrate is the refined form of natural sodium borate; it is commonly used for the production of borosilicate glasses, glass wool, ceramics, detergents, and fireproof materials. However, the main and most important application of borax is as a structure- and property-modifying agent in the manufacture of ceramic materials and high-quality glasses [2,3]. Borax decahydrate crystals with particular physical properties are required, such as particle size, caking properties, filtration characteristics, crystal morphology, and fluidity. In addition to the physical properties of borax crystals, the mechanical properties, which are described as the behaviors of materials under applied external forces, are important for industrial applications. The knowledge of these properties is crucial to establishing the fundamental principles for the design of molecular solids with desirable properties and to prevent failures in many engineering application areas [4]. One of the most widely studied mechanical properties of crystalline materials in the literature is hardness, which is generally defined as the resistance to deformation [5]. The hardness of crystalline materials can be measured using various tests, such as the static indentation test, dynamic indentation test, scratch test, rebound test, and abrasion test [6]. Among them, the indentation hardness test is suitable for engineering applications and the basis of this technique is used in the Vickers, Brinell, Meyer, and Rockwell methods [5,6]. In the Brinell method, a steel ball (for soft materials) or a tungsten carbide ball (for hard materials) is used with different loads (500 kg for soft materials and $3000 \mathrm{~kg}$ for hard materials). In the Meyer method, the hardness is determined based on the projected area of an impression. Although this is a more fundamental method of determining indentation hardness, it is not widely used for practical measurement. In the Rockwell method, the indentation depth under a constant load is used as a measure of hardness. This method is the most widely used owing to its speed, freedom from operator error, and the small indentation size [5]. In the Vickers method, a square-based diamond pyramid indenter with an angle of $136^{\circ}$ between the opposite face is used and the applied load ranges from $1 \mathrm{~kg}$ to $100 \mathrm{~kg}$ [6]. This method is more reliable owing to the continuous hardness scale for a given load when 
compared to other measurement methods [5]. On the other hand, it has several disadvantages, such as being slow, the need for careful surface preparation, and a high possibility of operator error in the determination of the diagonal length. [6]. The hardness of crystalline materials is influenced by several factors, such as indenter shape, indentation size, indentation time, loading force, loading rate, sample orientation, surface condition, and addition of additives $[7,8]$.

To date, several studies have been conducted related to the hardness of organic and inorganic crystals. Tavakoli et al. [9] investigated the effects of different nanodiamond impurities at various levels on $\mathrm{KCl}$ crystals. It was observed that the hardness of single $\mathrm{KCl}$ crystals increased depending on the increment of impurity percentage. Verma et al. [8] researched the influence of homovalent and aliovalent ions with different ionic radii on $\mathrm{KCl}, \mathrm{KBr}$, and $\mathrm{KCl}-\mathrm{KBr}$ crystals. It was found that the hardness of these crystals is load dependent and changed depending on the additives. Furthermore, brittle material characteristics were observed for all of the crystals in the presence of all impurities. Kishi et al. [10] studied the indentation hardness on the (110) habit plane of hen-egg white lysozyme crystals with intracrystalline water with various levels of relative humidity. A strong correlation was found between crystal hardness and water content in the crystals, which was related to the evaporation and humidity. Amala and Bindhu [11] researched the effects of $\mathrm{NaCl}$ on ammonium dihydrogen phosphate single crystals. Microhardness measurement was one of the studied properties in their project. Hardness tests were performed for three different loads of 25, 50, and 100 $\mathrm{g}$ for pure and $\mathrm{NaCl}$-doped ammonium dihydrogen phosphate. It was found that the crystal hardness of ammonium dihydrogen phosphate increased with the addition of $0.5 \% \mathrm{NaCl}$ and the authors concluded that $\mathrm{NaCl}$ addition enhanced the mechanical properties of ammonium dihydrogen phosphate crystals.

Obtaining more knowledge about the hardness of crystals helps understand the nature of the studied crystals and their crystallization mechanisms. Therefore, in this study, the microhardness of borax decahydrate was investigated using various polyelectrolytes as an additive. In addition, the thermal decomposition behavior of the samples was investigated and the functional groups of the crystals were determined. The results can be used as a guide to control the hardness of borax decahydrate crystals.

\section{Materials and methods}

Pure powdered borax decahydrate (Merck) and triple distilled water were used in all experiments. Single crystals of borax decahydrate were produced in pure and non-pure media. At the beginning of the experiment, according to solubility data obtained at $50{ }^{\circ} \mathrm{C}$, a saturated borax solution was prepared and filtered by utilizing a Millipore membrane filter with a $0.22 \mu \mathrm{m}$ pore size. Then, this solution was subjected to slow evaporation $\left(25^{\circ} \mathrm{C}\right)$ in the absence and the presence of various additives. Cationic and anionic polyelectrolytes were selected as the additives. The polyelectrolytes used in this work are detailed in Table 1. The polyelectrolyte concentrations were in the range of 0 to $100 \mathrm{ppm}$.

Transparent single crystals without any cracks and with flat, smooth faces were selected for microhardness measurements. The selected crystals were stored in a desiccator for 24 hours prior to the measurements. Figure 1 shows the SEM image of the hexagonal-shaped borax decahydrate crystal obtained in pure media. Vickers hardness indentations were applied to the asgrown (010) surface of the borax decahydrate crystals. The microhardness measurements were made using a microhardness device from Anton Paar Company in the indentation load range of 10 to $30 \mathrm{~g}$. The Vickers diamond pyramidal indenter was connected to a microscope with a specially converted video camera to measure the diagonal length of the indentations on a screen. An indentation time of $10 \mathrm{~s}$ was selected and at least twenty crystals were measured. The arithmetic mean of the measured diagonals was used to calculate the Vickers hardness number, $\mathrm{H}_{\mathrm{v}}$ in $\mathrm{kg} / \mathrm{mm}^{2}$, according to Eq. (1).

Table 1. Properties of polyelectrolytes used in this work.

\begin{tabular}{|c|c|c|c|c|c|}
\hline $\begin{array}{l}\text { Trade } \\
\text { Name }\end{array}$ & Producer & $\begin{array}{c}\text { Physical } \\
\text { State }\end{array}$ & Charge & $\begin{array}{l}\text { Physical } \\
\text { State }\end{array}$ & $\begin{array}{l}\text { Chemical } \\
\text { Structure }\end{array}$ \\
\hline FO4115 & $\begin{array}{c}\text { SNF } \\
\text { Floerger }\end{array}$ & Solid & $\begin{array}{c}\text { Cationic } \\
(\% 2)\end{array}$ & Powder & PAM+Metac \\
\hline FO4400 & $\begin{array}{c}\text { SNF } \\
\text { Floerger }\end{array}$ & Solid & $\begin{array}{c}\text { Cationic } \\
(\% 30)\end{array}$ & Powder & PAM+Metac \\
\hline FO4990 & $\begin{array}{l}\text { SNF } \\
\text { Floerger }\end{array}$ & Solid & $\begin{array}{l}\text { Cationic } \\
(\% 100)\end{array}$ & Powder & PAM+Metac \\
\hline AN923 & $\begin{array}{c}\text { SNF } \\
\text { Floerger }\end{array}$ & Solid & $\begin{array}{c}\text { Anionic } \\
(\% 20)\end{array}$ & Powder & PAM \\
\hline AN930 & $\begin{array}{c}\text { SNF } \\
\text { Floerger }\end{array}$ & Solid & $\begin{array}{c}\text { Anionic } \\
(\% 30)\end{array}$ & Powder & PAM \\
\hline AN999 & $\begin{array}{c}\text { SNF } \\
\text { Floerger }\end{array}$ & Solid & $\begin{array}{c}\text { Anionic } \\
\% 100\end{array}$ & Powder & PAM \\
\hline
\end{tabular}

PAM: Polyacrylamide Metac: Metacril trimethyl ammonium chloride 


$$
H_{v}=\frac{1.8544 P}{d^{2}}
$$

where $P$ is the indenter load in $\mathrm{kg}, d$ is the average diagonal length $(\mathrm{mm})$, and 1.8544 is a constant geometrical factor relating to the diamond pyramid. For a given indenter orientation, the dimensions of the different indentations produced on a sample at a given load did not differ from their average value by more than $1 \%$. For all the indentation loads tested, the indented surfaces were examined by microscope in reflection mode immediately after the hardness measurements in order to check the shape of the indentation impressions.

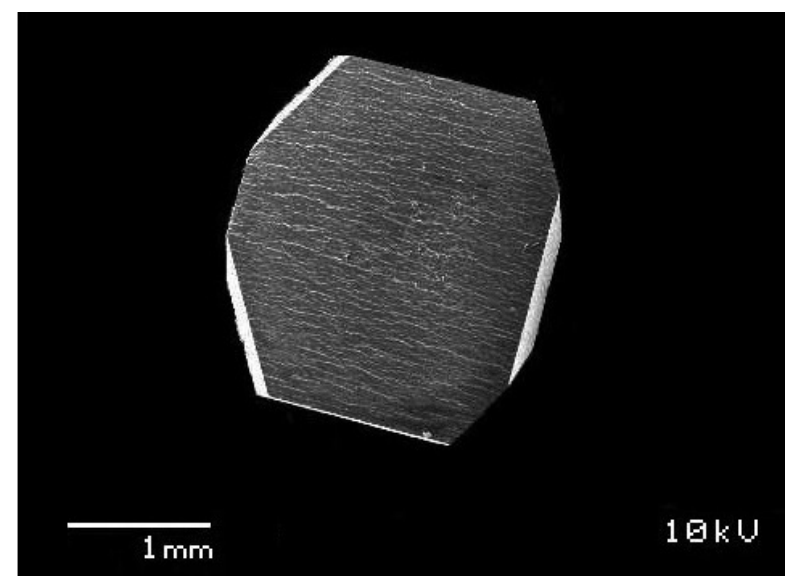

Figure 1. SEM image of borax decahydrate crystal grown in pure media.

In addition to the microhardness measurements, thermogravimetric (TG) and Fourier transform infrared spectrometer (FTIR) analyses were performed to characterize the borax decahydrate crystals. TG analysis was conducted using a Setaram Labsys Evo thermal analyzer. The analysis was performed in an aluminum crucible with a heating rate of $20{ }^{\circ} \mathrm{C} / \mathrm{min}$ under nitrogen atmosphere. FTIR analysis was performed using a Shimadzu IR Affinity-1 spectrometer to determine the functional groups and also to detect whether the additives had been adsorbed on the borax decahydrate surface. The spectra were recorded from 4000 to $400 \mathrm{~cm}^{-1}$ with eight scans per sample and a resolution of $4 \mathrm{~cm}^{-1}$.

\section{Results and discussion}

\subsection{Crystal hardness results}

The hardness of the borax decahydrate crystals produced by controlled solar evaporation technique in the absence and presence of cationic and anionic polyelectrolytes with different load intensities was measured and the obtained data were evaluated by utilizing different models. The changes in the borax decahydrate hardness for different indentation loads in different cationic and anionic polyelectrolytes media with different concentrations are presented in Figure 2 and 3 , respectively.
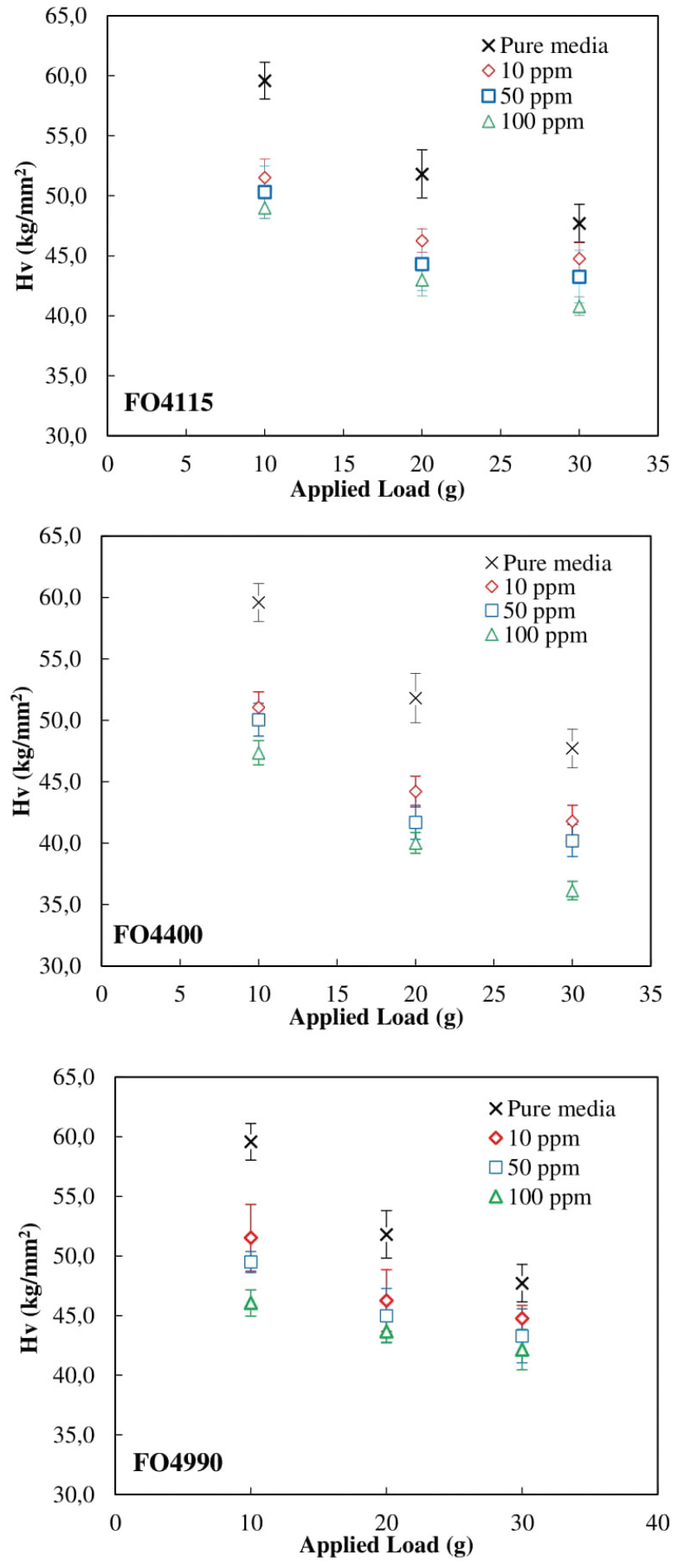

Figure 2. Variation of borax decahydrate microhardness as a function of the load range for pure and cationic polyelectrolyte media.

The hardness of the borax decahydrate obtained in pure media decreased with increasing applied load. This change also demonstrated a non-linear behavior. A similar effect was also seen in the presence of the anionic and cationic polyelectrolytes.

The change in the hardness of the crystals obtained both in pure media and in polyelectrolyte media depending on the applied load is termed the ISE (indentation size effect), as stated in the literature [12]. 

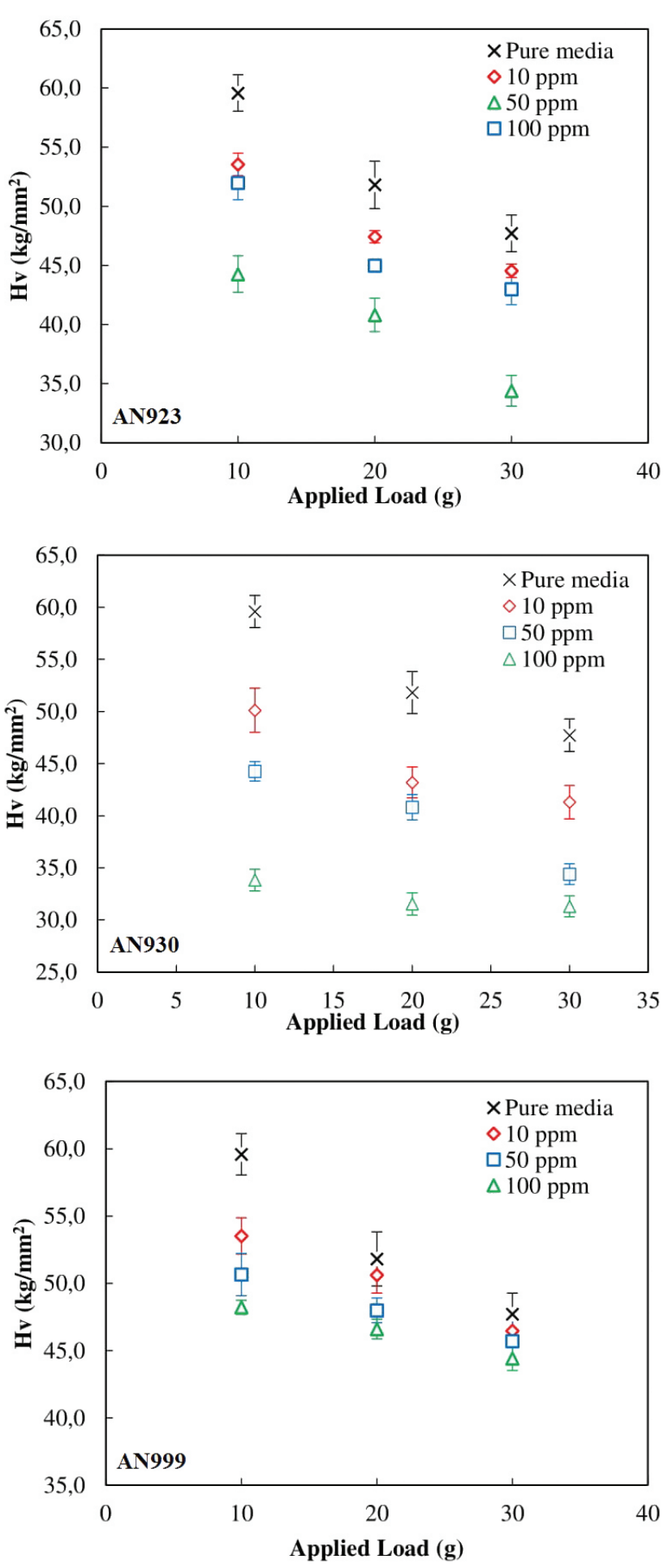

Figure 3. Variation of borax decahydrate microhardness as a function of the load range for pure and anionic polyelectrolyte media.

This effect may occur with the increase or decrease of measured hardness values depending on the applied load. When the effect is observed as an increment it is classed as normal ISE, while if the effect is observed as a decrement it is known as inverse ISE. Among these effects, normal ISE occurs as a result of elastic and plastic deformation, deformation of a plastic-plastic mixture, formation of dislocation rings during indentation, stresses owing to dislocations, and friction resistance between the indentation element and the crystal. On the other hand, inverse ISE occurs as a result of the existence of a deformative region on the crystal surface, vibration formation owing to the element forming the indentation surface at low loads, energy loss depending on crack. Meyer's law [13] was used to determine the extent of the ISE on the measured hardness values because Meyer's law can be used to determine normal and inverse ISE as described above. According to Meyer's law, there is a correlation (described in Eq. (2)) between the load applied in hardness measurements and the resulting indentation size, crush formation, and radial crack formation.

$$
P=A d^{n}
$$

where $A$ is constant parameter for a given material and $n$ is the Meyer index. The value of $n$ is less than 2 ( $n$ $<2)$ for normal ISE behavior, greater than $2(n>2)$ for inverse ISE behavior and equal to $2(n=2)$ for load-independent hardness. The results from the evaluation of the experimental data according to Meyer's law are given in Table 2.

Onitsch [14] and Hanneman [15] reported that values of $n$ greater than 1.6 indicate a crystal of soft material type and values of $n$ below 1.6 mean that the crystal falls is a hard material. The value of the work hardening coefficient obtained for borax decahydrate crystals obtained in pure media indicated a hard structure. As can be seen in Table 2, the values of $n$ lie between 1.605 and 1.899 and hence the borax decahydrate obtained in polyelectrolyte media is of a soft nature.

Meyer's law is simply an empirical expression that can be used to represent the relationship between indentation load and the resultant indentation size. It only gives valid results for a narrow range of indentation loads. Meyer's parameters were used for the characterization of the experimental data; however, the classical Meyer's law did not adequately describe our experimental data, which was better represented to a polynomial equation. Therefore, the proportional specimen resistance (PRS) model, which ideally characterizes normal ISE behavior, was utilized. Microhardness is described using two components in the PRS model. The first is the term taking into consideration the plastic and elastic deformation and the second is the loadindependent part. According to this model, the correlation between applied load, $P$, and indentation size of, $d$, is described as shown in Eq. (3).

$$
P=a_{1} d+a_{2} d^{2}
$$

When Eq. (3) is arranged, Eq. (4) is obtained.

$$
\bar{d}=a+\left(\frac{}{d}\right) d
$$


Table 2. Meyer's law parameters calculated for pure and additive media.

\begin{tabular}{|c|c|c|c|c|c|c|c|c|c|c|c|c|}
\hline \multirow{2}{*}{ 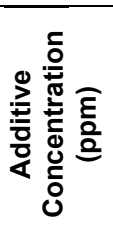 } & \multicolumn{6}{|c|}{ A } & \multicolumn{6}{|c|}{$n$} \\
\hline & 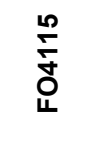 & $\begin{array}{l}\text { ᄋ } \\
\text { ষ } \\
\text { ơ }\end{array}$ & $\begin{array}{l}\text { \& } \\
\text { \& } \\
\text { 요 }\end{array}$ & $\begin{array}{l}\text { N } \\
\text { Z }\end{array}$ & $\begin{array}{l}\text { ㅇ } \\
\text { g } \\
\text { Z }\end{array}$ & $\begin{array}{l}\text { g } \\
\text { 号 } \\
\text { ¿ }\end{array}$ & 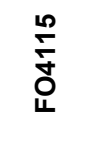 & $\begin{array}{l}\text { ㅇ } \\
\text { 寸 } \\
\text { 요 }\end{array}$ & $\begin{array}{l}\text { \& } \\
\text { ᄋ } \\
\text { 요 }\end{array}$ & 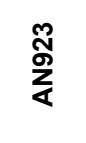 & $\begin{array}{l}\text { ㅇ } \\
\text { o } \\
\text { ¿ }\end{array}$ & $\begin{array}{l}\text { \% } \\
\text { g } \\
\text { 인 }\end{array}$ \\
\hline 0 & 8.274 & 8.274 & 8.274 & 8.274 & 8.274 & 8.274 & 1.464 & 1.464 & 1.464 & 1.464 & 1.464 & 1.464 \\
\hline 10 & 6.863 & 7.965 & 9.432 & 8.612 & 5.890 & 12.06 & 1.643 & 1.605 & 1.740 & 1.695 & 1.636 & 1.779 \\
\hline 50 & 10.01 & 6.868 & 10.49 & 9.152 & 8.010 & 15.39 & 1.749 & 1.656 & 1.729 & 1.712 & 1.694 & 1.866 \\
\hline 100 & 11.04 & 5.431 & 13.92 & 9.707 & 10.83 & 18.31 & 1.768 & 1.686 & 1.852 & 1.723 & 1.862 & 1.899 \\
\hline
\end{tabular}

In this equation, $a_{1}$ is a constant parameter, $P_{c}$ is the applied load where the microhardness value becomes load-independent, and $d_{0}$ is the diagonal length of the indentation. The hardness value is transformed into load-independent form by using the value obtained as a result of the linear regression stated in Eq. (4) between $P / d$ and $d$ in the Vickers equation. The results obtained from the evaluation of the obtained experimental data according to the PRS model are presented in Figure 4.
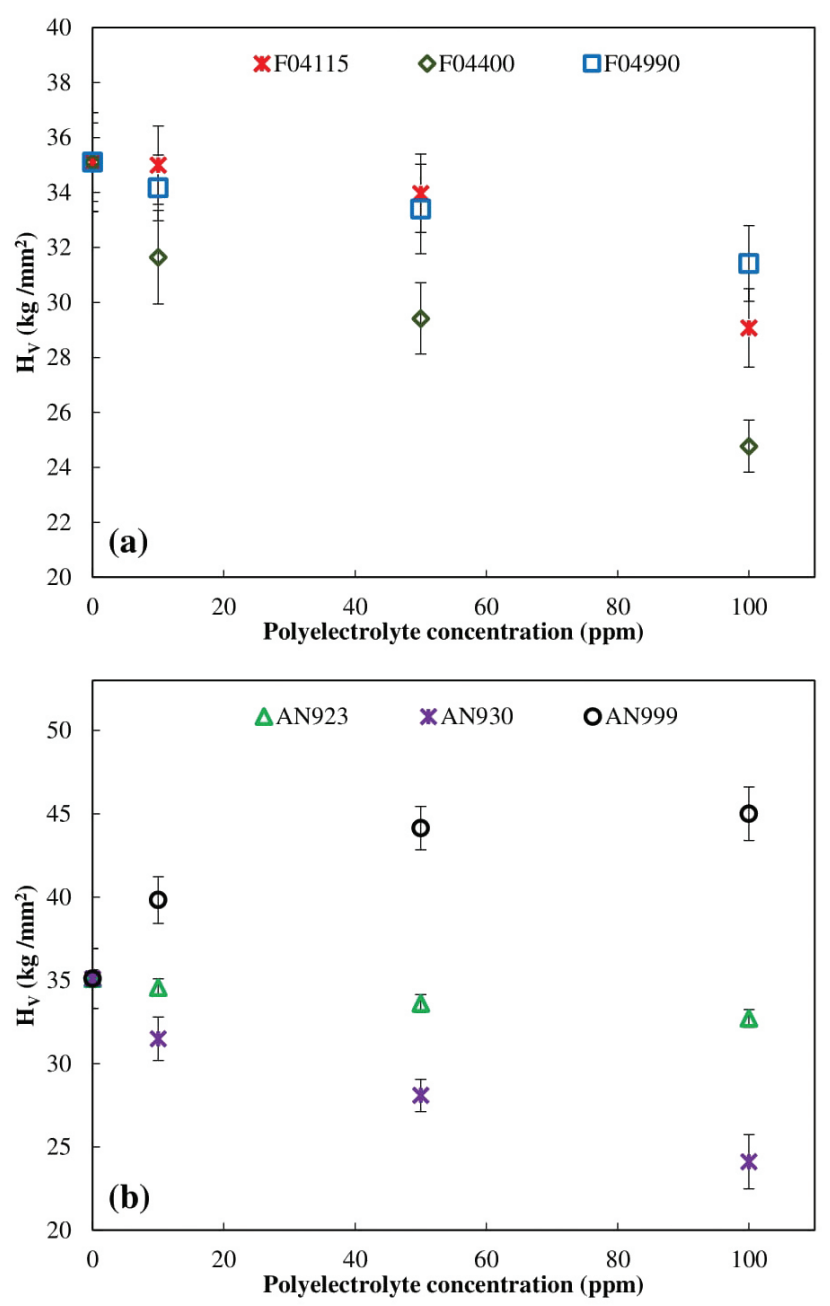

Figure 4. Variation of borax decahydrate microhardness $\left(H_{v}\right)$ with (a) cationic polyelectrolyte and (b) anionic polyelectrolyte concen tration.
As can be seen from Figure 4, in the presence of AN999 polyelectrolytes, the hardness of the borax decahydrate crystals increases with increasing additive concentration. This was because the introduction of the additive in the crystal lattice of borax decahydrate created an ionic vacancy, which acts as an obstacle to dislocation motion, thus increasing the hardness of the crystal. On the other hand, the presence of the other studied polyelectrolytes in the crystallization media caused a decrease in the $H_{v}$ value. The effect of the additive type on the hardness could be seen more clearly at higher additive concentrations. While AN930 caused the biggest change, AN923 had the lowest effect among the polyelectrolytes studied.

\subsection{FTIR analysis}

The FTIR spectra of the borax decahydrate produced in pure and polyelectrolyte media were collected for the qualitative determination of their chemical structure. Figure 5 shows the FTIR spectra of the crystals in the range of $400-4000 \mathrm{~cm}^{-1}$.

The transmittance bands at $\sim 3400 \mathrm{~cm}^{-1}$ and $\sim 1650$ $\mathrm{cm}^{-1}$ represent the $\mathrm{O}-\mathrm{H}$ stretching and $\mathrm{H}-\mathrm{O}-\mathrm{H}$ bending vibrations. The peak at $\sim 1432 \mathrm{~cm}^{-1}$ was attributed to the asymmetric stretching of the $\mathrm{B}-\mathrm{O}$ bond in $\mathrm{BO}_{3}$. The bands at 1130 and $1080 \mathrm{~cm}^{-1}$ are characteristic of asymmetric stretching of the $\mathrm{B}-\mathrm{O}$ bond in $\mathrm{BO}_{4}$. Two bands at approximately $950 \mathrm{~cm}^{-1}$ and $830 \mathrm{~cm}^{-1}$ denoted the presence of symmetric stretching of $\mathrm{B}-\mathrm{O}$ in $\mathrm{BO}_{3}$ and $\mathrm{BO}_{4}$, respectively. All the observed bands confirm the formation of borax decahydrate crystals [16]. Similar to the pure media, characteristic borax decahydrate peaks were detected in the presence of the additives. However, no distinctive and characteristic peaks related to the additives used could be detected owing to the overlapping of the characteristic peaks of the polyelectrolytes with the borax decahydrate peaks. On examining the FTIR spectra, it was seen that the band at $3600-3200 \mathrm{~cm}^{-1}$ was broadened in the presence of the polyelectrolytes. This could be attributed to the incorporation of the additives in the borax decahydrate. Furthermore, the slightly shifting behavior and changing peak intensity observed resulted from the adsorption of the polyelectrolytes on borax decahydrate. 


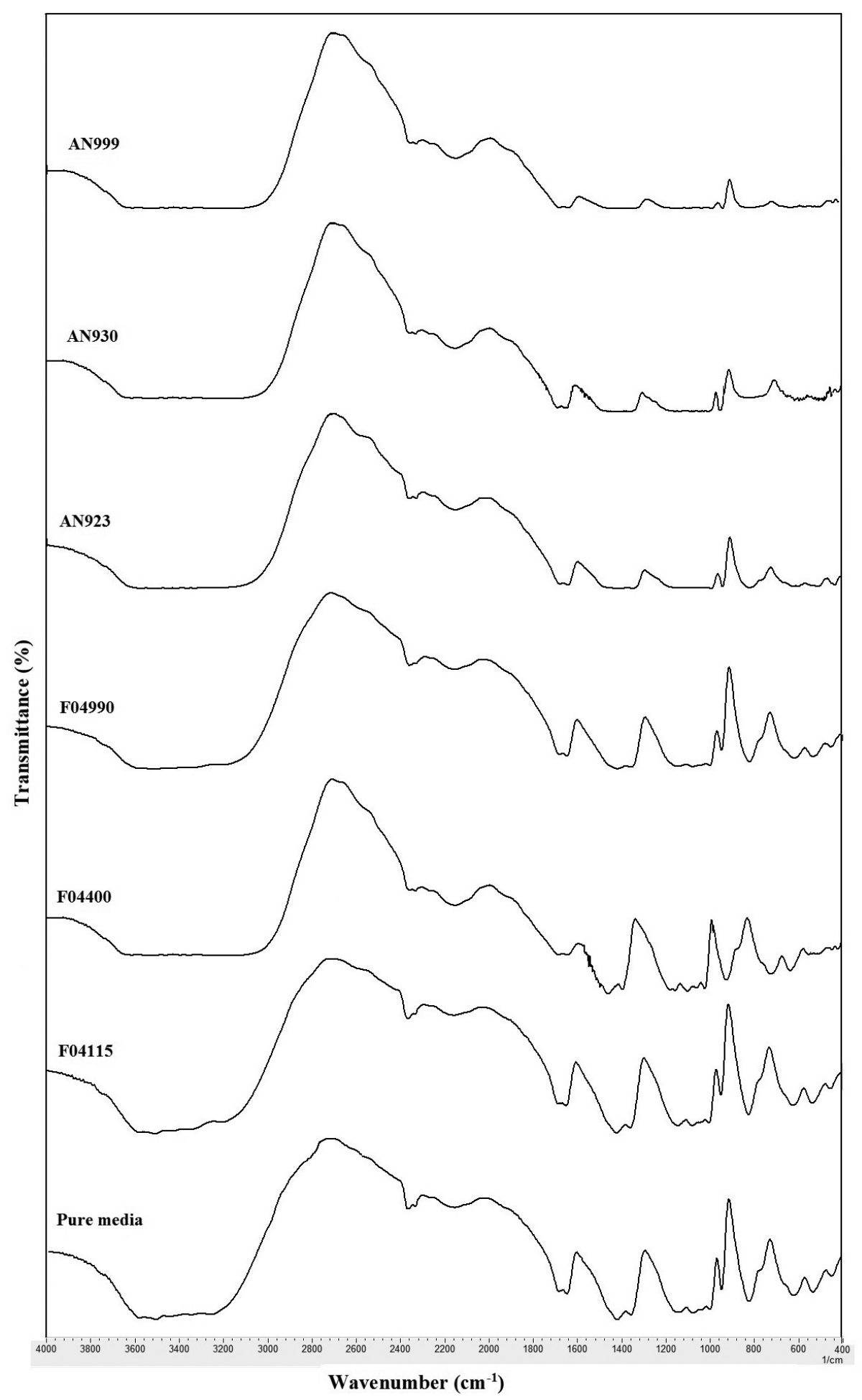

Figure 5. FTIR spectra of borax decahydrate obtained in pure and polyelectrolyte media.

\subsection{Thermal analysis}

The thermal properties of the borax decahydrate grown in pure media and in the presence of polyelectrolytes were determined using a thermogravimetric analyzer. The thermogravimetric (TG) and differential thermogravimetric (DTG) curves of the crystals are shown in Figure 6.

The thermal degradation curve of the crystals obtained in pure media showed two weight loss regions. The curve showed that the first and second decomposition zones were in the temperature ranges of $67-154{ }^{\circ} \mathrm{C}$ and $156-223^{\circ} \mathrm{C}$, representing the removal of crystal water within their chemical structure [17]. The total weight loss for pure media during the thermal decomposition at $500{ }^{\circ} \mathrm{C}$ was $\sim 48 \%$. In the polyelectrolyte media, in addition to the two peaks described above, new peaks were detected in the DTG curves and the weight loss increased slightly owing to the crystals containing both the additive and borax decahydrate. 

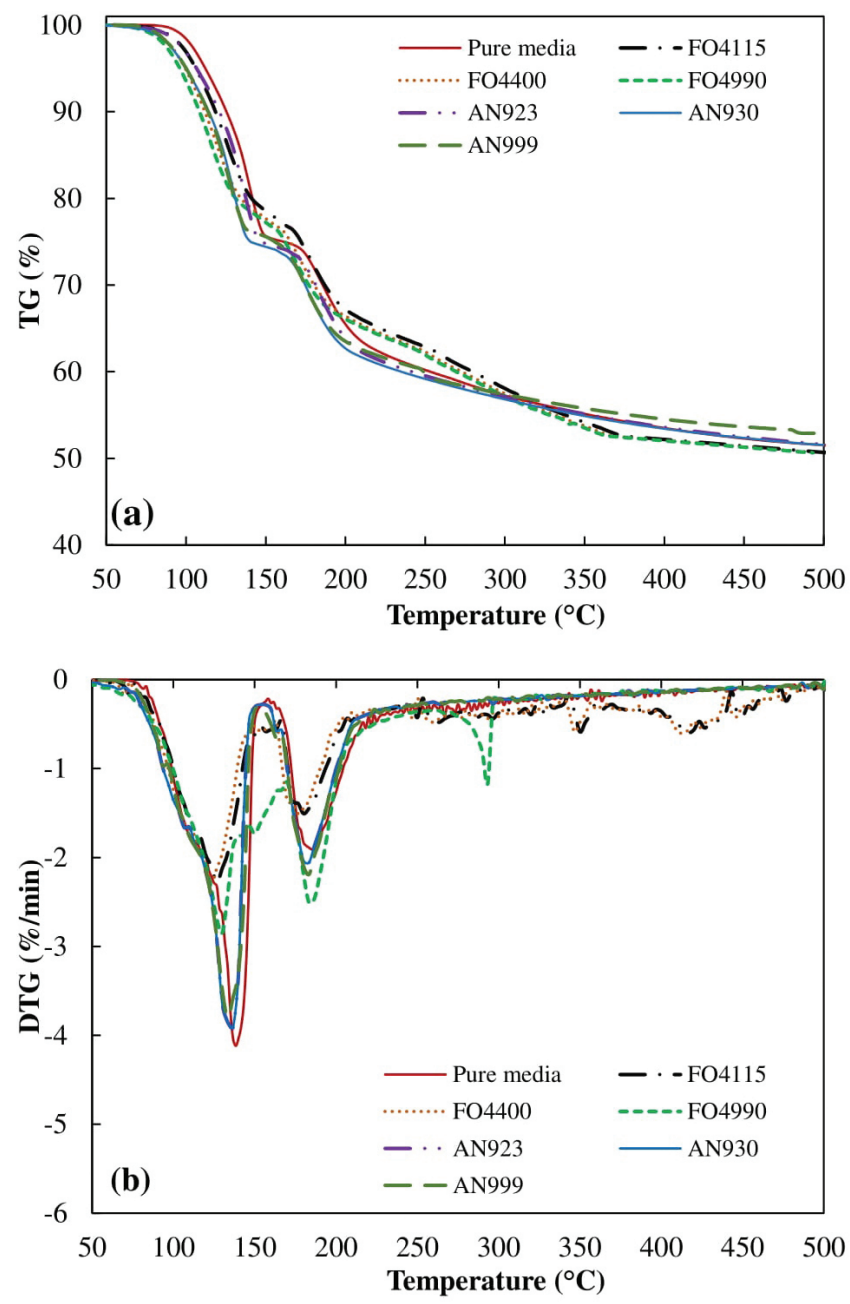

Figure 6. (a) TG and (b) DTG curves of borax decahydrate grown in pure and polyelectrolyte media.

For instance, the final decomposition between 335$360{ }^{\circ} \mathrm{C}$ with a peak at $350{ }^{\circ} \mathrm{C}$ and $273-300{ }^{\circ} \mathrm{C}$ with a peak at $293{ }^{\circ} \mathrm{C}$ for $\mathrm{FO} 4115$ and $\mathrm{FO} 4990$ additive media were attributed to polyelectrolyte decomposition. It was observed that the crystals containing various polyelectrolytes were more thermally stable when compared to the crystals obtained in pure media.

\section{Conclusions}

The aim of this study was to investigate the effects of cationic and anionic polyelectrolytes on the hardness of borax decahydrate crystals. The main conclusions obtained are summarized below:

- Crystal hardness of borax decahydrate was affected by the load intensity of the microhardness test and the concentration of the polyelectrolytes.

- The Meyer index was found to be less than $2(n<2)$ as a result of the evaluation of the measured hardness value according to Meyer's law. This situation demonstrated that there was a normal ISE on the measured values. Furthermore, the obtained results revealed that the borax decahydrate crystals grown in pure media had a brittle structure.
- The PRS model was used for the evaluation of normal ISE. The change of the crystal hardness values depending on the polyelectrolyte concentration was determined by transforming the measured values into load-independent form. The crystal hardness changed in the presence of the polyelectrolytes.

- According to the PRS model, FO4400 polyelectrolyte was found to be more effective than the other cationic polyelectrolyte as an additive under the same conditions in terms of its effects on crystal hardness.

- The TG and DTG results showed that the polyelectrolytes were adsorbed on the crystal surface and the borax decahydrate crystals grown in additive media were thermally more stable than those grown in pure media.

- As a result, this study demonstrated that polyelectrolytes can be effectively used as additives for modifying the hardness of borax decahydrate crystals.

\section{References}

[1] McMillian P. W., Glass-Ceramics, $2^{\text {nd }}$ edition, Academic Press, New York, 1979.

[2] Ceyhan A. A., Sahin Ö., Bulutcu, A. N., Crystallization kinetics of the borax decahydrate, J. Cryst. Growth, 300 (2), 440-447, 2007.

[3] Gurbuz H., Ozdemir B., Experimental determination of the metastable zone width of borax decahydrate by ultrasonic velocity measurement, J. Cryst. Growth, 252 (1-3), 343-349, 2003.

[4] Mannepalli S., Mangalampalli K. S. R. N., Indentation plasticity and fracture studies of organic crystals, Crystals, 7, 324, 2017.

[5] Dieter G. E., Mechanical Metallurgy, Mc Graw Hill, New York, 1961.

[6] Suresh S., Techniques and tools used for investigating the grown crystals: Review, Latin-American Phys. Educ., 6 (4), 547-558, 2012.

[7] Tian Y., Xu B., Zhao Z., Microscopic theory of hardness and design of novel superhard crystals, Int. J. Refract. Met. Hard Mater., 33, 93-106, 2012.

[8] Verma A. K., Ojha C., Shrivastava A. K., Effects of impurities on the hardness of alkali halide single crystals, AIP Conf. Proc., 1591, 1242, 2014.

[9] Tavakoli M. H., Abasi T. A., Ali E. H., Growth of $\mathrm{KCl}$ crystal by Czochralski method and influence of nanodiamond impurity on its hardness and optical properties, Cryst. Res. Technol., 48 (3), 130-137, 2013.

[10] Kishi T., Suzuki R., Shigemoto C., Murata H., Kojima K., Tachibana M., Microindentation hardness of proteins crystals under controlled relative humidity, Crystals, 7 (11), 339, 2017.

[11] Amala B. M., Bindhu M. R., Studies on the effect of 
sodium chloride on ammonium dihydrogen phosphate single crystals, IJERT, 4 (9), 315-318, 2017.

[12] Ding S., Zhang Q., Liu W., Luo J., Sun G., Sun D., Crystal growth, defects, mechanical, thermal and optical properties of $\mathrm{Tb}_{3} \mathrm{Sc}_{2} \mathrm{Al}_{3} \mathrm{O}_{12}$ magneto-optical crystal, J. Cryst. Growth, 483,110-114, 2018.

[13] Meyer E., Contribution to the knowledge of hardness and hardness testing, Z. ver, Dtsch. Ing. 52, 645-654, 1908.

[14] Onitsch E. M., Micro-hardness testing, Mikroscopia. 2, 131-151, 1947.
[15] Hanneman M., Metall. Manchu. 23, 135, 1941.

[16] Goel N., Sinha N., Kumar B., Growth and properties of sodium tetraborate decahydrate single crystals, Mater. Res. Bull. 48 (4), 1632-1636, 2013.

[17] Guo J., Chen, X., Zhang Y., Improving the mechanical and electrical properties of ceramizable silicone rubber/halloysite composites and their ceramic residues by incorporation of different borates, Polymers, 10 (4), 388, 2018. 